\section{UJMM

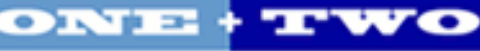

Volume 7| 2017 Spring 2017

\section{Undergraduate Journal of Mathematical} Modeling: One + Two

2017

\title{
Alternative Typing Learning Curves
}

Marcel Kreuzer

University of South Florida

Advisors:

Arcadii Grinshpan, Mathematics and Statistics

Peter McAlindon, Founder and CEO, Blue Orb Inc.; Entrepreneur in Residence, Rollins College

Problem Suggested By: Peter McAlindon

Follow this and additional works at: https://digitalcommons.usf.edu/ujmm

Part of the Mathematics Commons

UJMM is an open access journal, free to authors and readers, and relies on your support:

Donate Now

\section{Recommended Citation}

Kreuzer, Marcel (2017) "Alternative Typing Learning Curves," Undergraduate Journal of Mathematical Modeling: One + Two: Vol. 7: Iss. 2, Article 6.

DOI: http://doi.org/10.5038/2326-3652.7.2.4881

Available at: https://digitalcommons.usf.edu/ujmm/vol7/iss2/6 


\title{
Alternative Typing Learning Curves
}

\begin{abstract}
Typing is a part of everyday life for many people. However some people have difficulty in doing it. For example, for people who are blind and those who have carpal tunnel or cerebral palsy, a standard keyboard would not be effective to type. Alternative options include voice recognition and keyless keyboards. We focus on orbiTouch keyboard which has no keys, only two knobs which allow a person to type. Which alternative way of typing would be most effective given a person's condition is discussed.
\end{abstract}

\section{Keywords}

alternative typing, orbiTouch keyboard, learning curve

Creative Commons License

(c) (i) (\$)

This work is licensed under a Creative Commons Attribution-Noncommercial-Share Alike 4.0 License. 


\section{PROBLEM STATEMENT}

To find the best alternative form of typing given one's physical disability.

\section{Motivation}

Any new technology as an alternative for typing should not be more difficult than the regular one. The new typing alternatives need to be easy to learn and still produce a reasonable typing speed compared to regular typing. Each of these forms of typing and keyboards has a learning curve. We need to calculate the learning curve and use it to figure out the most effective form of alternative typing. In particular, we need to determine the incremental increase per time. Showing mathematically how fast a person with disability can learn will help to determine the best method of typing for her/him.

\section{MATHEMATICAL DESCRIPTION AND SOLUTION APPROACH}

We will compare people with three different cases, all using the orbiTouch keyless keyboard. We will create a learning curve for the orbiTouch keyboard for someone with carpal tunnel, cerebral palsy, and a regular person. Then we will produce one learning curve for the voice recognition method of typing. It would make no sense to create three different learning curves since these disabilities are physical. Speaking is a cognitive process and using a keyboard is a physical one. We first start out with the basic form of a learning curve, where the $P$ value would be performance in words per minute as a function of time $t$ in hours: 


$$
P(t)=\frac{w p m \max }{\left(1+d e^{-w p m \max * k t}\right)}
$$

This learning curve is the general solution of the three parameter logistic differential equation. The numerator in (1) is the maximum of words per minute a person can achieve with their given condition. The variable $d$ would be its "incremental growth". The $k$ value would be another parameter, which is a person's "ability to learn". It is obvious that the larger $k$ is, the quicker someone will be able to achieve her/his typing goal.

Let us first create our learning curve for a theoretical case for a person with carpal tunnel syndrome using the orbiTouch keyless keyboard. We assume a person with carpal tunnel can only reach a max of $30 \mathrm{wpm}$ having an initial rate wpm of 1 and in one hour of practice achieving 2 wpm. We use the differential equation (2) and solution (3) to it which corresponds to the learning curve formula (1):

$$
\begin{gathered}
\frac{d P}{d t}=k P(30-P) \\
P(t)=30 /\left(1+d e^{-30 k t}\right)
\end{gathered}
$$

Then we plug the initial value for $P$ and 0 for time into (3) to find constant $d$ :

$$
\begin{gathered}
1=\frac{30}{1+d} \\
d=29
\end{gathered}
$$

Now we can plug $d=29$ into (3). Then we place the given information $P=2$ when $t=1$ to determine parameter $k$ :

$$
\begin{gathered}
2=30 /\left(1+29 e^{-30 k(1)}\right) \\
15=1+29 e^{-30 k} \\
k \approx 0.0243
\end{gathered}
$$


Having both the $d$ and $k$ values, we plot our learning curve (4) for the orbiTouch for people with carpal tunnel syndrome, Figure (1):

$$
P(t)=\frac{30}{1+29 e^{-.0243 t * 30}}=30 /\left(1+29 e^{-0.729 t}\right)
$$

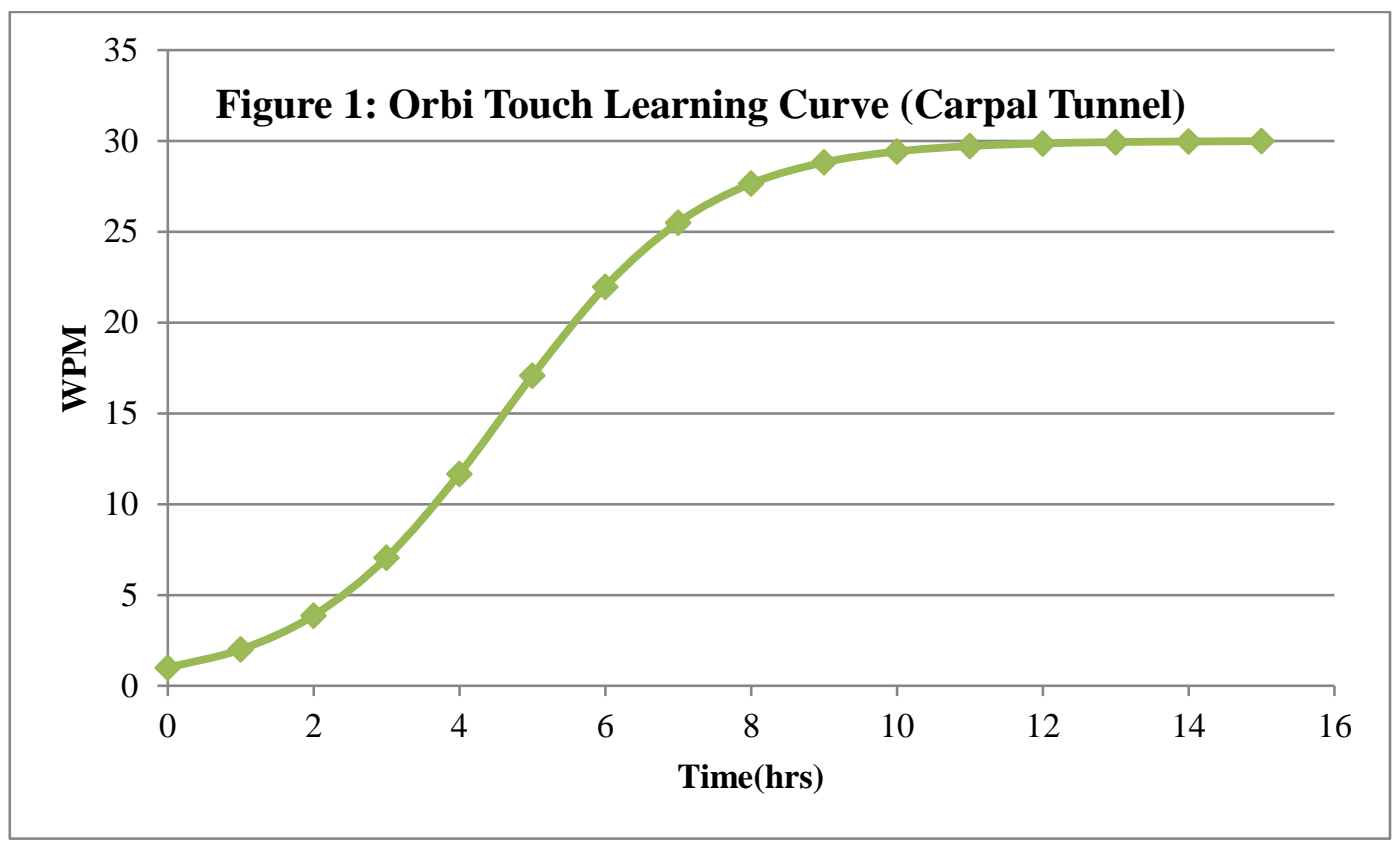

Next we create our learning curve for a person with cerebral palsy using the orbiTouch keyless keyboard. We assume that someone with cerebral palsy can only reach $20 \mathrm{wpm}$. Initially they can type at a rate of $1 \mathrm{wpm}$. After one hour of practice, they can type $1.5 \mathrm{wpm}$. We use the differential equation (5) and solution (6) to this equation:

$$
\begin{gathered}
\frac{d P}{d t}=k P(20-P) \\
P(t)=20 /\left(1+d e^{-20 k t}\right)
\end{gathered}
$$

We plug the initial performance at $t=0$ into (6) to find constant $d$ or the incremental growth value:

$$
1=\frac{20}{1+d}
$$




$$
d=19
$$

Then we plug $d$ into (6). Also, we plug $P=1.5$ when t=1 into (6) to find $k$ :

$$
\begin{gathered}
1.5=20 /\left(1+19 e^{-20 k(1)}\right) \\
20 / 1.5=1+19 e^{-20 k} \\
k \approx 0.0216
\end{gathered}
$$

Now that we have both $k$ and $d$, we can plot our learning curve (7) for people with cerebral palsy using the orbiTouch keyless keyboard, Figure (2):

$$
P(t)=\frac{20}{1+19 e^{-.0216 t * 20}}=20 /\left(1+19 e^{-0.432 t}\right)
$$

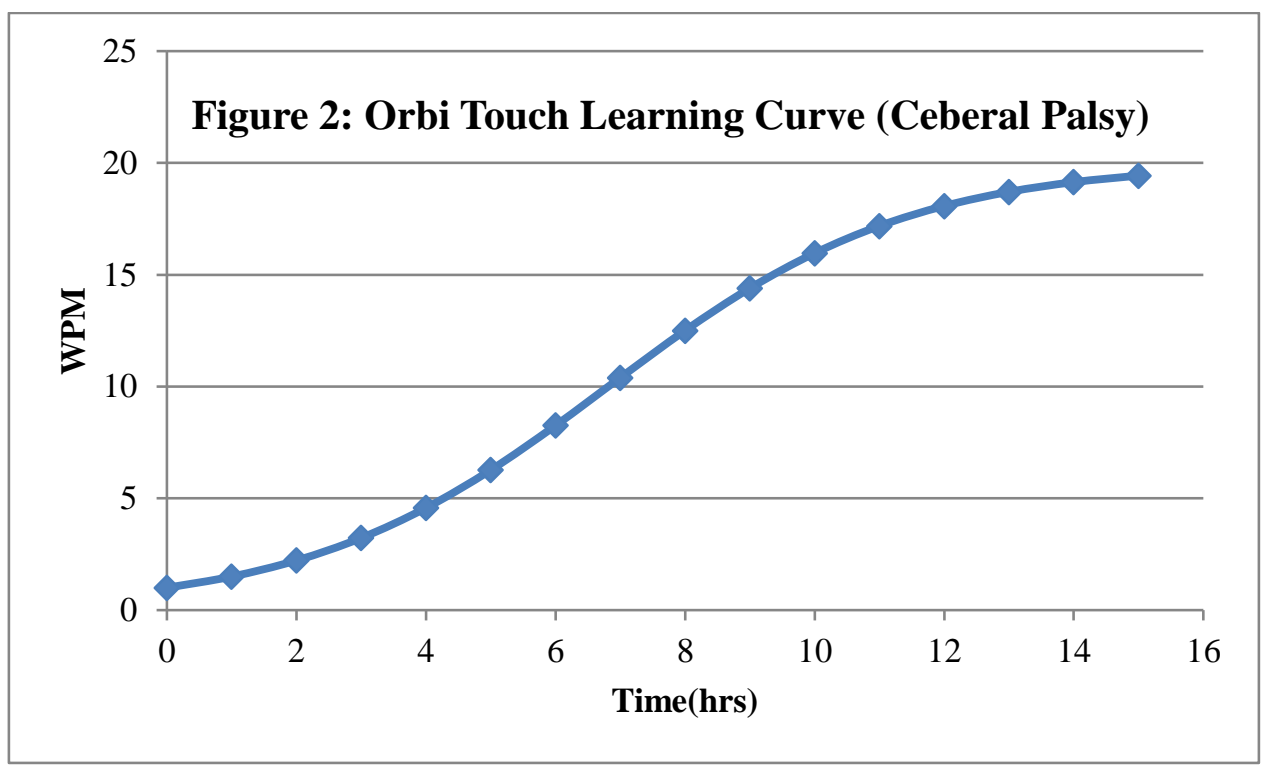

Next, let us create our learning curve for a person without disability who uses the orbiTouch. We assume that such a person can only reach a max of $40 \mathrm{wpm}$, typing at a rate of $1 \mathrm{wpm}$ at the beginning, and after one hour of practice - at a rate of $3 \mathrm{wpm}$. We have the corresponding differential equation (8) and its solution (9):

$$
\frac{d P}{d t}=k P(40-P)
$$




$$
P(t)=40 /\left(1+d e^{-40 k t}\right)
$$

To find the $d$ value, we plug $t=0$ and $P=1$ wpm into (9):

$$
\begin{gathered}
1=\frac{40}{1+d} \\
d=39
\end{gathered}
$$

Now that we have our $d$ value, we plug $P=3$ when $\mathrm{t}=1$ into formula (9). We obtain $k$ :

$$
\begin{gathered}
3=40 /\left(1+39 e^{-40 k(1)}\right) \\
40 / 3=1+39 e^{-40 k} \\
k \approx 0.0288
\end{gathered}
$$

Having both the $k$ and $d$ values, we can graph our learning curve (10) for a person without disability who uses the orbiTouch, Figure (3):

$$
P(t)=\frac{40}{1+39 e^{-.0288 t * 40}}=40 /\left(1+39 e^{-1.152 t}\right)
$$

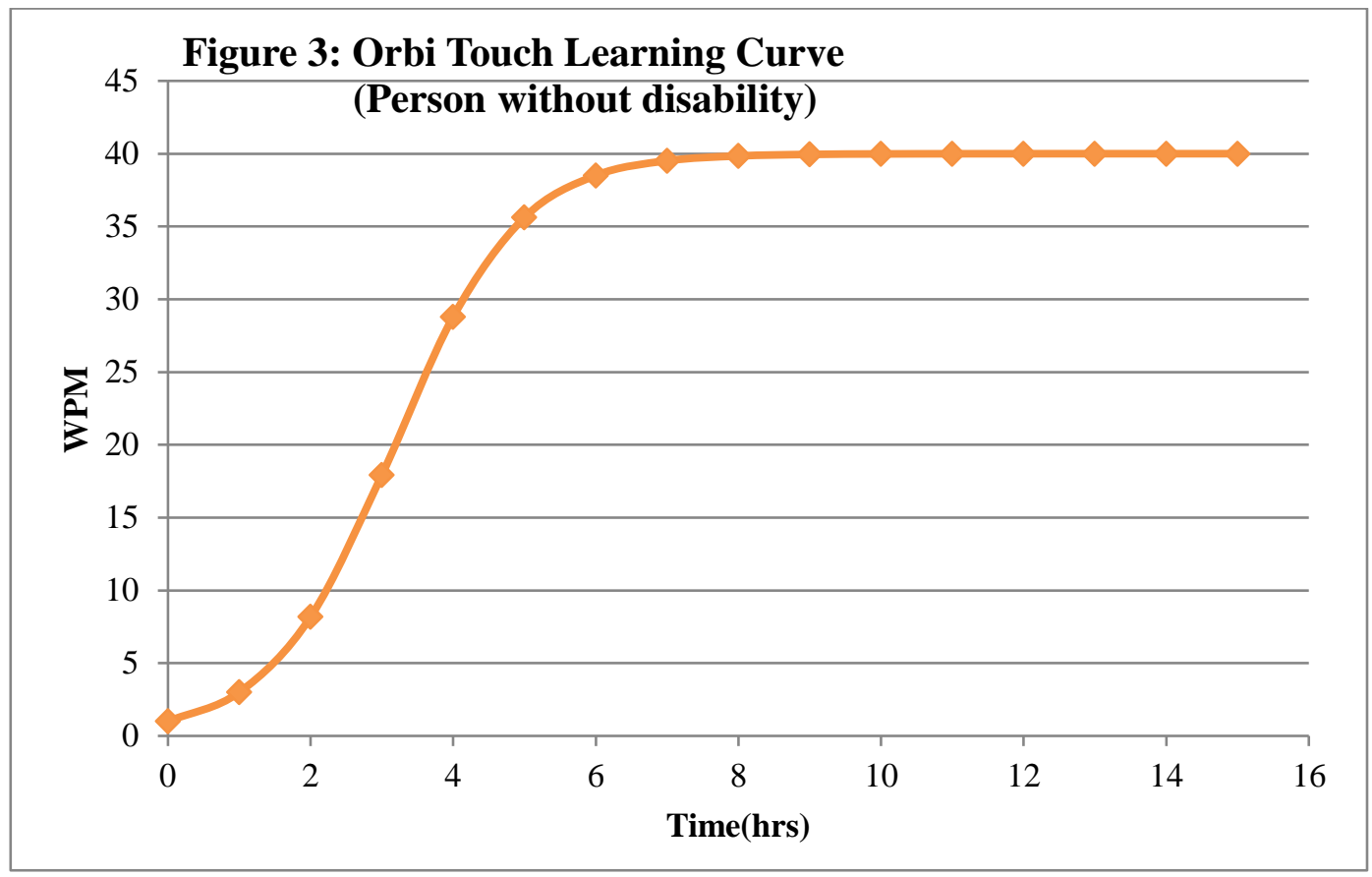

Finally, let us create a learning curve for someone using the voice control method of typing. We assume that the max wpm a person can get is $130 \mathrm{wpm}$. We also assume that a 
person initially starts at $100 \mathrm{wpm}$ and after 1 hour of practice - at a rate $105 \mathrm{wpm}$. We have differential equation (11) and its solution (12).

$$
\begin{gathered}
\frac{d P}{d t}=k P(130-P) \\
P(t)=130 /\left(1+d e^{-130 k t}\right)
\end{gathered}
$$

We plug $t=0$ and $P=100$ into (12) to determine our $d$ value.

$$
\begin{aligned}
100 & =\frac{130}{1+d} \\
d & =0.3
\end{aligned}
$$

We plug constant $d$ into (9), along with the given $t=1$ and $P=105$. By plugging these values into (12) we solve for $k$ value:

$$
\begin{gathered}
105=130 /\left(1+0.3 e^{-130 k(1)}\right) \\
130 / 105=1+0.3 e^{-130 k} \\
k \approx 0.00178
\end{gathered}
$$

Now with both the $k$ and $d$ values, we are able to graph our learning curve (13) for voice command typing, Figure (4):

$$
P(t)=\frac{130}{1+0.3 e^{-0.00178 t * 130}}=130 /\left(1+0.3 e^{-0.231 t}\right)
$$




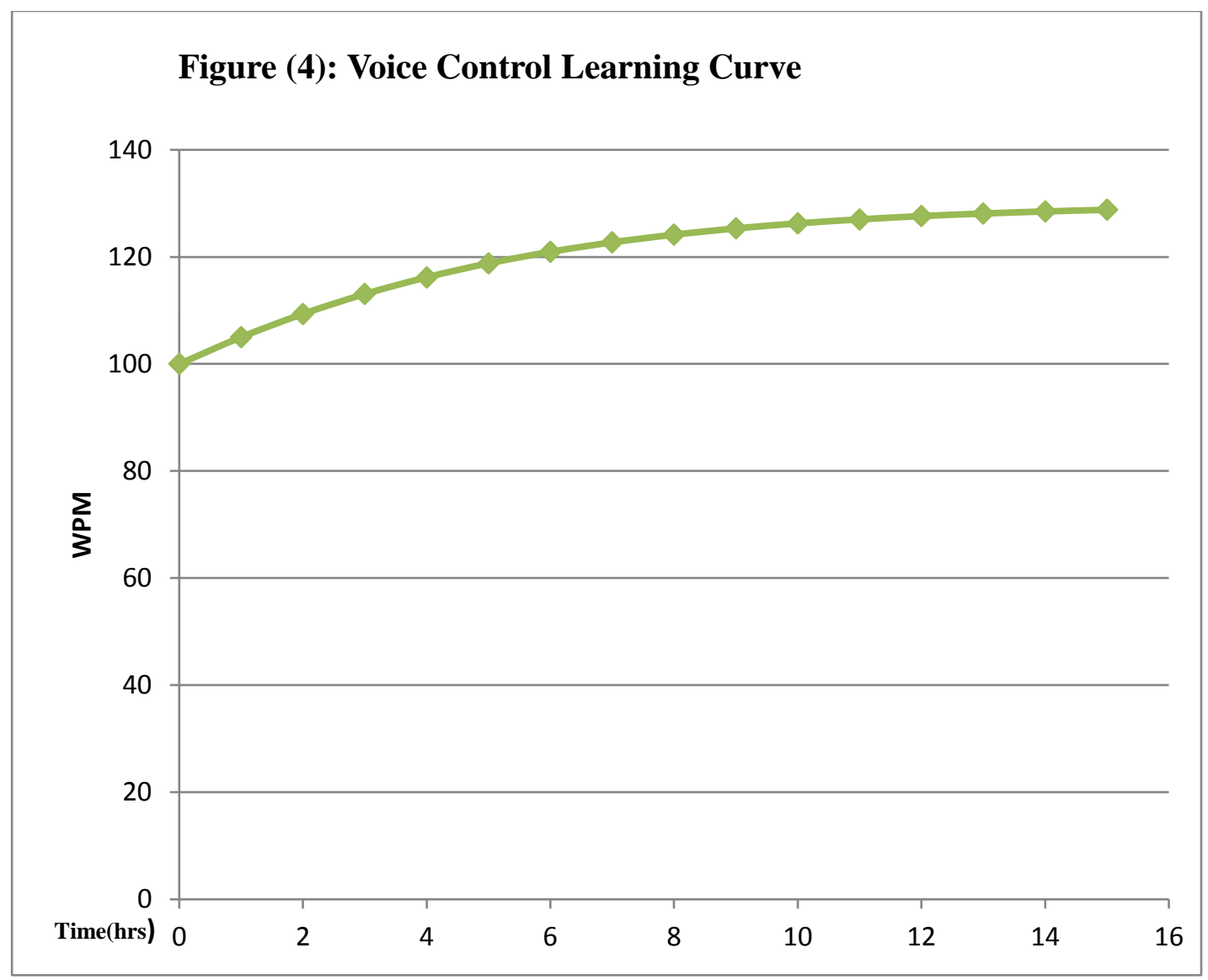

\section{DISCUSSION}

We found three learning curves for an orbitTouch keyless keyboard and a learning curve for voice recognition. There would be no need to create three different voice recognition curves as speaking is a cognitive process, not a physical one. We found that people with cerebral palsy had a lower incremental growth " $d$ " $(d=19)$ and learning capability " $k$ " $(k=0.0216)$ compared to the values $d=29$ and $k=0.0243$ for the people with carpal tunnel syndrome who have more ability to move their hands and wrists. This makes sense because it would be harder for someone to increase their performance if they have a larger disability. Voice recognition technically has no learning curve. We grow up our whole lives speaking to people every day. So, your wpm growth 
with voice recognition will not be large because you already know how to speak, we can see this with the $d$ and $k$ values of our curve. The $d$ value for voice recognition is 0.3 which is much smaller than the other $d$ values we have. This makes sense because there is not a lot of room to increase speed with speaking, which makes the learning curve graph much flatter. Our $k$ value for voice recognition is 0.00178 which is also the smallest $k$ value we have. It is reasonable because someone's learning capability will be smaller: it is hard to improve something you are already fast at.

\section{CONCLUSION AND RECOMMENDATIONS}

In conclusion, the received data did correspond to the logic behind it. As we tested learning curves for people using an orbiTouch keyboard, we saw the relationship between our $k$ and $d$ values with our performance function. As the $d$ value increased, we saw that our incremental growth was increasing as well. This is safe to say that our $d$ value is that incremental growth. People with cerebral palsy had a lower incremental growth than people with carpal tunnel if they use the orbiTouch keyboard. This makes sense because they have less potential to increase their wpm everyday due to their more severe disability. Also, we can see as $k$ increases, the learning capability increases too. It is safe to say that the $k$ value is a person's learning capability. Our data do correspond to this: if a person's disability is less severe, than the $k$ value is greater because they have more potential to learn. In fact, people with different disabilities have a different learning curve for every device they are trying to adapt to. We wanted to find an alternative keyboard that will not inhibit someone's typing capabilities with a reasonable 
learning curve. The orbiTouch keyless keyboard may not let you type as fast as a normal keyboard, but it allows people with disabilities to continue with their work day on the computer. We can fully conclude that the orbiTouch keyless keyboard is an effective way of typing for people with disability for a short period of time. If a researcher wants to conduct a similar project, we would recommend to focus on someone's learning capability and incremental growth by just looking at their mental state, not a physical one, and then compare the results to physical conditions. 


\section{NOMENCLATURE}

\begin{tabular}{|c|c|c|}
\hline Symbol & Description & Value \\
\hline wpm & Words per Minute & words $/ \mathrm{min}$ \\
\hline $\mathrm{P}$ & Performance & wpm \\
\hline$t$ & Time & hours \\
\hline $\mathrm{k}$ & Learning Capability & \\
\hline $\mathrm{d}$ & Incremental Growth & \\
\hline
\end{tabular}

\section{REFERENCES}

James Stewart, Essential Calculus: Early Transcendentals, 2nd ed. 2013, Cengage Learning.

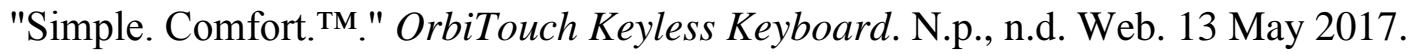

Writer, Leaf Group. "What Is a Good Typing Speed Per Minute?" Chron.com. Chron.com, 26

Oct. 2016. Web. 13 May 2017.

smallbusiness.chron.com /good-typing-speed-per-minute-71789.html

"Thread." Derivative of Exponential Function (average Typing Speed N). N.p., n.d. Web. 13

May 2017.

https://www.freemathhelp.com/forum/threads/55977-Derivative-of-Exponential-Function(average-typing-speed-N) 